Gut, 1965, 6, 266

\title{
Effect of age on liver function with particular reference to bromsulphalein excretion
}

\author{
EILEEN N. THOMPSON AND ROGER WILLIAMS
}

From the Department of Medicine, Royal Free Hospital, London

EDITORIAL SYNOPSIS This paper is of practical importance to those interested in liver disease and alimentary haemorrhage. The authors have shown a clear tendency for liver function, largely measured by the infusion of bromsulphalein, to fall with increasing age.

Little is known about the effect of age on liver function. The only study to date is that of Rafsky and Newman (1943) who found increased retention of bromsulphalein in 16 of 39 normal subjects over the age of 70 years compared with a group of 11 subjects aged 60 to 70 years. Liver weight is known, however, to decrease with age. Boyd (1933) analysed 9,886 necropsies and found that the decrease, which was significant statistically after the age of 50 years, was most marked over 70 . A marked sex difference was also shown, with a $20 \%$ reduction in the mean liver weight in male subjects over the age of 70 years compared with $11 \%$ in women of the same age. Unfortunately no clinical details were given and no attempt was made to correlate liver with total body weight. Such a correlation would be of help in establishing whether the increased bromsulphalein retention was due to a decrease in size of the liver with a reduction of the functioning cell mass.

Such an ageing effect may have clinical implications and the present study was done to assess further its frequency and the factors responsible. The study is divided into two parts. In the first, the excretion of bromsulphalein and other liver function tests are examined in detail in a group of normal subjects of widely differing ages. The second part consists of a necropsy study in which the relation of the liver weight to age and total body weight at various ages is considered.

\section{LIVER FUNCTION}

MATERIAL AND METHODS Thirty-two male volunteer subjects were examined whose ages ranged from 20 to 93 years. In none was there any history or clinical evidence of liver disease or of congestive cardiac failure. Straight radiographs of the chest and abdomen were within normal limits. The excretion of bromsulphalein was studied in two ways. First, the retention of the dye in the plasma at 30 minutes after the intravenous injection of a dose of $5 \mathrm{mg}$. $/ \mathrm{kg}$. body weight was determined. Blood samples were taken at five-minute intervals during this period and the 30-minute retention was calculated by expressing the plasma level at this time as a percentage of that present at zero time, the latter being determined by extrapolation backwards of the initial part of the curve plotted on semi-log paper. Secondly, the relative storage capacity (S) and secretory transport maximum (Tm) for bromsulphalein were measured by the technique of Wheeler, Meltzer, and Bradley (1960). In this method, the values for $S$ and $T m$ are derived indirectly from comparison of the rates of disappearance of bromsulphalein from the plasma during two different constant infusions of the dye. Care was taken to ensure that the plasma concentration throughout the period of the test was greater than $3 \mathrm{mg} . / 100 \mathrm{ml}$. The relative storage capacity is a measure of the processes responsible for the uptake and storage of bromsulphalein in the liver. The amount stored in the liver is proportional to the plasma concentration and $S$ is expressed as the number of milligrams of dye stored per milligram per $100 \mathrm{ml}$. of the plasma concentration. The subsequent excretion of bromsulphalein into the bile has, like many other active secretory processes, a maximal rate known as the 'secretory transport maximum' which is measured in milligrams per minute. The serum bilirubin, alkaline phosphatase, albumin, and transaminase levels were estimated by standard methods.

RESULTS The patients have been divided into groups according to their age. In all groups the serum bilirubin, alkaline phosphatase, transaminase, and albumin levels were within normal levels. The 30-minute retention of bromsulphalein was also normal up to the age of 60 (Fig. 1). In four of the eight subjects aged 60 to 70 and in all eight of those over the age of 70, the retention was increased with values ranging up to $15 \%$, the upper limit of normal being $10 \%$.

The results of the measurements of relative storage 


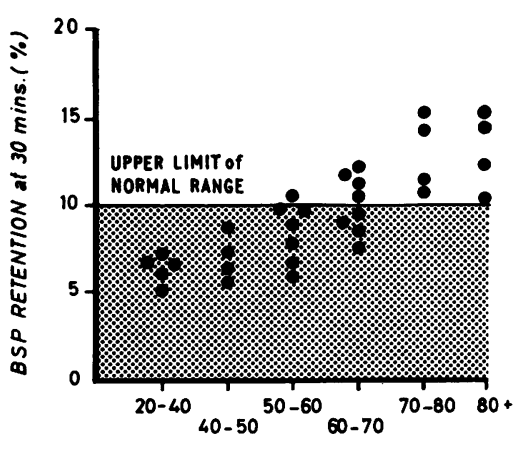

AGE GROUPS

FIG. 1. Results of the bromsulphalein retention test (5 mg./kg. body weight) in 32 normal male subjects.

capacity (S) and secretory transport maximum (Tm) showed that with respect to $\mathrm{Tm}$ there was no difference between the values found in the different decades. The mean for the whole group of 9.3 mg./min. (S.D. 2.0) agreed closely with the figure of 9.1 (S.D. 1.4) found by Williams, Preisig, Sweeting, and Bradley (1963) in a group of healthy normal subjects aged 20 to 40 . Low values for $S$ were found in a number of patients after the age of 50 (Fig. 2). These were the same patients who showed an increased $30 \mathrm{~min}$. retention of bromsulphalein following a single intravenous dose. If the 20 to 40 and 40 to 50 age groups are considered together, the mean value for $\mathrm{S}$ is $83 \mathrm{mg} . / \mathrm{mg} . \%$ (S.D. 15) which is very similar to that found (75 S.D., 17) in the normal group of Williams et al. (1963). From the age of 50 onwards, an increasing proportion had a lower storage capacity (Fig. 2). The mean values in the age groups after 50 are significantly different from the mean value in the 20 to 50 group (Table I). If the subjects are simply divided into those above and below the age of 50 there is also a significant inverse

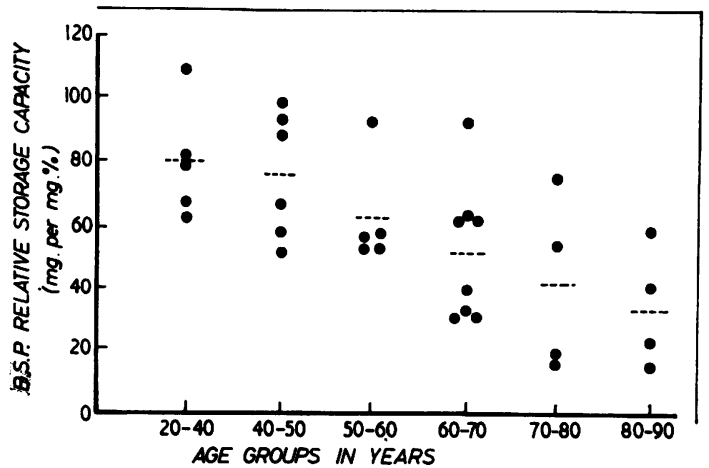

FIG. 2 Values for the relative storage capacity of the liver for bromsulphalein in the various age groups. correlation between age and $\mathrm{S}$ above that age $(\mathrm{r}=$ $-0.54, \mathrm{p}<0.01, \mathrm{n}=23)$ but not below $(\mathrm{r}=0.21$, $\mathrm{p}>0.05, \mathrm{n}=9$ ).

\section{TABLE I}

STATISTICAL ANALYSIS (STUDENT'S T TEST) OF VALUES FOR BROMSULPHALEIN RELATIVE STORAGE CAPACITY IN GROUPS OVER 50 YEARS COMPARED WITH VALUES IN NINE NORMAL SUBJECTS AGED 20 TO 50

\begin{tabular}{lccc} 
Age Group (yr.) & No. of Patients & $t$ & $p$ \\
\hline $80-90$ & 4 & 3.7 & $<0.01$ \\
$70-80$ & 4 & $3 \cdot 1$ & $=0.01$ \\
$60-70$ & 8 & 2.5 & $<0.05$ \\
$50-60$ & 7 & 2.7 & $<0.02$
\end{tabular}

Clinically there were no distinguishing features between the elderly subjects with a low value for $\mathbf{S}$ and those with normal values except perhaps for the fact that they appeared older than their chronological age. Total body weight decreased after the age of 50 , the inverse correlation found achieving statistical significance $(\mathrm{r}=-0.45, \mathrm{p}<0.05)$. There was no correlation, however, between the decrease in weight and the reduction in $\mathrm{S}(\mathrm{r}=0.22, \mathrm{p}>0.05)$. Below the age of 50 there was also no relation between total body weight and $S(r=0.21, p>0.05)$.

\section{NECROPSY STUDY}

MATERIAL AND METHODS The total body weight and liver weight in 206 male subjects aged 23 to 93 years were analysed. The cause of death was due to trauma, infection, or coronary artery disease. They represent consecutive necropsies done over the last three years, with the exception of patients with liver disease or neoplasia, who were excluded.

RESULTS In order to facilitate comparison the patients have been divided into the same age groups as those used for the bromsulphalein studies. The mean liver weights in these groups, together with the standard deviations, are shown in Figure 3. The mean liver weight decreases after the age of 50 , but the range in the first two groups is wide and only the values in the 70 to 80 and 80 to 90 groups are significantly different from those in the 20 to 50 group (Table II). If 50 years is taken as the dividing line there is a significant inverse correlation between age and liver weight above that age $(r=-0.47$, $\mathrm{p}<0.001, \mathrm{n}=181)$ but not below $(\mathrm{r}=-0.15$, $\mathrm{p}>0.05, \mathrm{n}=25$ ).

Total body weight also decreased with age (Fig. 4, Table II). The inverse correlation found achieved statistical significance after the age of $50(r=0.45$, $\mathrm{p}<0.001)$ but not below $(\mathrm{r}=-0.12, \mathrm{p}>0.05)$. Both above and below that age there was a significant correlation between total body and liver weight 


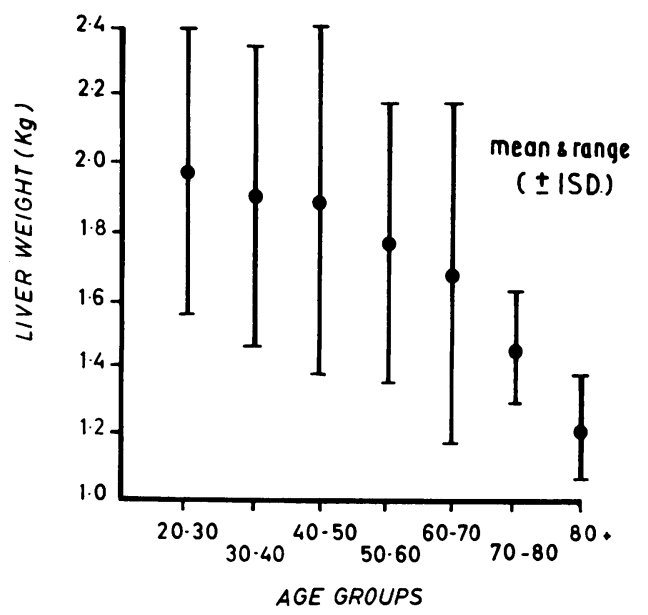

FIG. 3. The mean and range of liver weights in the necropsy series.

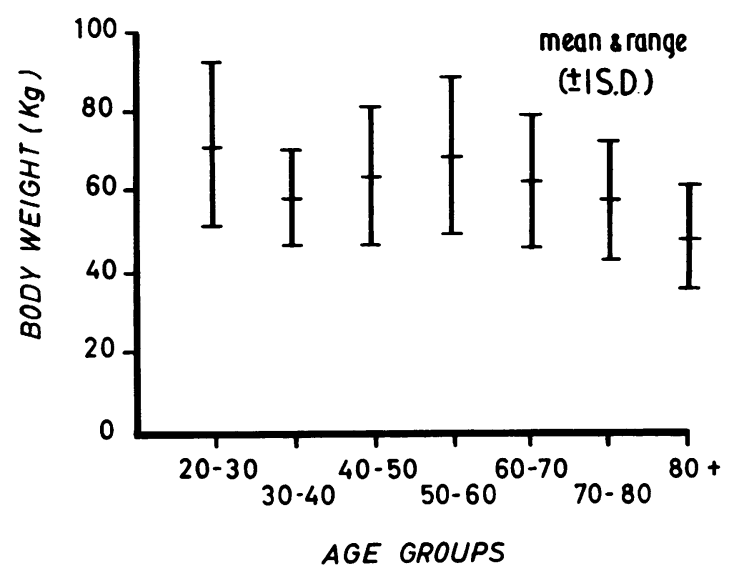

FIG. 4. The mean and range of total body weight in the necropsy series.

$(\mathrm{r}=0.29, \mathrm{p}<0.001, \mathrm{n}=181$ and $\mathrm{r}=0.57, \mathrm{p}<0.01$ $\mathrm{n}=25$ respectively).

\section{DISCUSSION}

The findings of the first part of the study show that an increasing proportion of apparently normal subjects over the age of 50 years have impaired hepatic function as judged by abnormalities of bromsulphalein excretion. It is important to emphasize that all known causes of liver disease had
TABLE II

STATISTICAL ANALYSIS (STUDENT'S T TEST) OF VALUES FOR LIVER AND TOTAL BODY WEIGHTS FOUND AT NECROPSY IN THE GROUPS AGED OVER 50 COMPARED WITH VALUES IN 25 SUBJECTS AGED 20 TO 50 AT TIME OF DEATH

\begin{tabular}{|c|c|c|c|c|c|}
\hline \multirow{2}{*}{$\begin{array}{l}\text { Age Group } \\
(y r .)\end{array}$} & \multirow{2}{*}{$\begin{array}{l}\text { No. of } \\
\text { Cases }\end{array}$} & \multicolumn{2}{|c|}{ Liver Weight } & \multicolumn{2}{|c|}{ Total Body Weight } \\
\hline & & $t$ & $p$ & $t$ & $p$ \\
\hline $80-90$ & 21 & $4 \cdot 2$ & $<0.001$ & $3 \cdot 1$ & $<0.01$ \\
\hline $70-80$ & 53 & 2.7 & $<0.01$ & 1.44 & $>0.05$ \\
\hline $60-70$ & 64 & 1.7 & $>0.05$ & $1 \cdot 22$ & $>0.05$ \\
\hline $50-60$ & 43 & $1 \cdot 1$ & $>0.05$ & 0.8 & $>0.05$ \\
\hline
\end{tabular}

been excluded, including congestive heart failure which is common in the elderly subject, and the subjects finally examined represented a very carefully selected group. Although the results of more standard liver function tests, notably the measurement of the serum bilirubin, albumin, and alkaline phosphatase levels were normal, numerous studies have shown that impaired bromsulphalein excretion is the most sensitive index of liver function and may be found when all other tests are within normal limits.

The excretion of bromsulphalein by the liver is complex and dependent on the two independent processes of storage (S) in the cell and active secretion in the bile (Tm) already defined. Previous studies (Wheeler et al., 1960; Williams et al., 1963) have shown that these functions can be altered to different extents, according to the type of disease present. For instance, in extrahepatic biliary obstruction and in the rare Dubin-Johnson variety of congenital jaundice it is the excretory $\mathrm{Tm}$ which is affected and storage capacity usually remains within normal limits. In infective hepatitis and in cirrhosis, where there is diffuse hepatocellular involvement, both $\mathbf{S}$ and $\mathrm{Tm}$ are reduced. In our elderly patients it was $\mathbf{S}$ which was affected and $\mathrm{Tm}$ remained within normal limits even in the oldest age group. The only other condition in which there is a selective reduction in $\mathbf{S}$ is in extrahepatic portal hypertension due to a portal vein thrombosis (Thompson, Williams, and Sherlock, 1964). It is of interest in relation to the present findings that the decreased $\mathbf{S}$ found in the latter condition was related to the age of the patient rather than to the duration of the disease, though in each age group the level of $\mathbf{S}$ was lower than that found in the normal controls.

The mechanism responsible for this selective reduction in $\mathbf{S}$ with age is uncertain. It would be tempting to relate it to the decrease in liver weight and presumably of functioning cell mass, found both by Boyd (1933) and by us to occur after the age of 50 . In the present necropsy series, however, there was a close correlation between the reduction in liver weight and the overall decrease in total body weight 
whereas in the normal subjects there was no correlation between $\mathbf{S}$ and body weight. Thus by inference it would appear that the reduction in $\mathbf{S}$ was not related to a decrease in liver weight. Furthermore there was no corresponding decrease in $\mathrm{Tm}$, which might have been expected if the cause was a simple reduction in functioning cell mass. The reduction in liver weight with age may be due to a decrease in supporting tissue and further studies are needed.

It would appear more likely therefore that the reduced $S$ is due to a localized defect in the liver cell. Little is known about the processes responsible for the uptake and storage of bromsulphalein. It is maintained in the cell at a concentration several times greater than those of the plasma which may involve a liver protein with a greater affinity for bromsulphalein than the plasma proteins or alternatively an active transport mechanism. Part of the bromsulphalein is conjugated with glutathione before excretion in the bile, the rate of conjugation being dependent on the presence of an enzyme which has been isolated from soluble supernatant fractions of both rat and human liver homogenates (Combes, and Stakelum, 1961 ; Javitt, Wheeler, Baker, Ramos, and Bradley, 1960). The capacity for storage, however, is not dependent on conjugation, and experimental reduction of conjugating 'ability' resulted in a reduction in $\mathrm{Tm}$ but not of $\mathrm{S}$ (Combes, 1962). It is of interest that the reverse situation, notably an increase in $S$, is consistently found in the later stages of pregnancy though the mechanism again is unknown (Combes, Shibata, Adams, Mitchell, and Trammell, 1963).

In conclusion it is of course true that the liver is not normally exposed to bromsulphalein but it seems reasonable to suppose that the impaired excretion is a reflection not only of impaired hepatic function but also of decreased hepatic tolerance for a variety of drugs and other agents normally excreted by the liver. This may explain the increased susceptibility to narcotics and other drugs observed in the elderly subject.

\section{SUMMARY}

Liver function was assessed in 32 male subjects with ages ranging from 20 to 93 years. Below the age of
50 no abnormality could be detected. Above that age an increasing proportion showed abnormal bromsulphalein retention although the other liver function tests remained within normal limits.

The impaired bromsulphalein excretion was due to a reduction in the storage capacity of the liver for the dye. The secretory transport maximum showed no change with age. Total body weight also decreased significantly after the age of 50 but there was no correlation between this and the reduction in storage capacity.

The results of a separate necropsy showed that liver weight as well as total body weight decreased after the age of 50. At all ages there was a significant correlation between liver and total body weight.

Since storage capacity did not correlate with total body weight, it seems improbable that its decrease with age is due to a reduction in liver weight and functioning cell mass. A selective cellular abnormality would appear more likely.

We are indebted to Dr. M. Hamilton and Professor Sheila Sherlock for allowing us to examine their patients. Mr. John Hendley gave valuable technical assistance and the work was supported by the Ingram Trust.

\section{REFERENCES}

Boyd, E. (1933). Normal variability in weight of the adult human liver and spleen. Arch. Path., 16, 350-372.

Combes, B. (1962). The importance of conjugation with glutathione on sulfobromophthalein (B.S.P.) transport from blood to bile. $J$. clin. Invest., 41, 1351.

_-, Shibata, H., Adams, R., Mitchell, B. D., and Trammell, V. (1963). Alterations in sulfobromophthalein sodium-removal mechanisms from blood during normal pregnancy. Ibid., 42, 1431-1442.

- - , and Stakelum, G. S. (1961). A liver enzyme that conjugates sulfobromophthalein sodium with glutathione. Ibid., 40, 981-988.

Javitt, N. B., Wheeler, H. O., Baker, K. J., Ramos, O. L., and Bradley, S. E. (1960). The intrahepatic conjugation of sulfobromophthalein and glutathione in the dog. Ibid., 39, 1570-1577.

Rafsky, H. A., and Newman, B. (1943). Liver function tests in the aged (the serum cholesterol partition, bromsulphalein, cephalin-flocculation and oral and intravenous hippuric acid tests). Amer. J. dig. Dis., 10, 66-69.

Thompson, E. N., Williams, R., and Sherlock, S. (1964). Liver function in extrahepatic portal hypertension. Lancet, 2, 1352-1356.

Wheeler, H. O., Meltzer, J. I., and Bradley, S. E. (1960). Biliary transport and hepatic storage of sulfobromophthalein sodium in the unanaesthetized dog, in normal man, and in patients with hepatic disease. J. clin. Invest., 39, 1131-1144.

Williams, R., Preisig, R., Sweeting, J., and Bradley, S. E. (1963). Storage and transport of bromsulphthalein in hepatitis and other liver diseases. Gut, 4, 89. 